\title{
Perpetuating Myths, Fables, and Fairy Tales: A Half Century of Electronic Fetal Monitoring
}

\author{
Thomas P. Sartwelle ${ }^{1}$ James C. Johnston ${ }^{2}$ Berna Arda $^{3}$ \\ 1 Beirne, Maynard and Parsons, LLP, Houston, Texas, United States \\ 2 Legal Medicine Consultants, Seattle, Washington, United States \\ ${ }^{3}$ Department of Medical Ethics, University of Ankara, Ankara, Turkey \\ Address for correspondence James $C$. Johnston, MD, JD, Legal \\ Medicine Consultants, 321 High School Road, Suite D3-750, Seattle, \\ WA 98110, United States (e-mail: johnston@GlobalNeurology.com).
}

Surg J 2015;1:e28-e34.

\begin{abstract}
Electronic fetal monitoring (EFM) entered clinical medical practice at the same time bioethics became reality. Bioethics changed the medical ethics landscape by replacing the traditional Hippocratic benign paternalism with patient autonomy, informed consent, beneficence, and nonmaleficence. But EFM use represents the polar opposite of bioethics' revered principles-it has been documented for half a century to be completely ineffectual, used without informed consent, and harmful to mothers and

Keywords

- cerebral palsy

- electronic fetal monitoring

- medical ethics

- medical education

- medical malpractice newborns alike. Despite EFM's ethical misuse, there has been no outcry from the bioethical world. Why? This article answers that question, discussing EFM's history and the reasons it was issued an ethics pass. And it explores the reason that even today mothers are still treated with blatant medical paternalism, deprived of autonomy and informed consent, and subjected to real medical risks under the guise that EFM is an essential safety device when in fact it is used almost solely to protect physicians and hospitals from cerebral palsy lawsuits.
\end{abstract}

Doctors are men who prescribe medicines of which they know little, for diseases about which they understand even less, for people about whom they know nothing.

-Voltaire

Every time a mother is hooked up to an electronic fetal monitor (EFM), she subjects herself and her baby to potential but undisclosed harm, including death, injury, disability, and the very real possibility of chronic lifelong disease. These potential consequences have been known to medicine since the inception of EFM, yet remain undisclosed to millions of mothers. Rather, EFM has been sold to patients as a necessary safety device.

It has become popular for physicians today to concede that EFM has been without evidence of clinical efficiency for the nearly half century of its use in monitoring the vast majority of pregnant women in the industrialized world. ${ }^{1-6}$ Conceding EFM's uselessness, and even acknowledging EFM's potential to cause some harm-primarily by compelling unnecessary cesarean sections-it has been equally popular for EFM

received

September 10, 2015

accepted after revision

October 9, 2015

published online

November 20, 2015 10.1055/s-0035-1567880. ISSN 2378-5128. proponents to argue for continued clinical use of the modality. These arguments are consistently affirmed by birth-related professional organizations (BRPOs) worldwide. ${ }^{1-6}$

These are prodigiously astounding arguments. Not only do EFM proponents ignore the vast hoards of empirical evidence of EFM-induced harm to mother and babies, but they ignore logic and reason as well. Even more importantly, EFM proponents also purposely flout the bedrock bioethical principles of autonomy, beneficence, and nonmaleficence by advocating continued EFM use, in particular EFM use without mothers' informed consent. And despite the arguments for continued EFM use being totally devoid of ethics, there has been no protest from organized medicine, BRPOs, clinicians, or ethicists. EFM has received an ethics pass.

Why has the medical world remained virtually silent while a machine known to be junk science has been presented to laboring mothers for nearly a half century cleverly disguised as a device necessary for safe delivery that can predict the baby's future? Because the reason EFM is used in virtually every labor is as a defense by physicians, nurses, and hospitals

Copyright $\odot 2015$ by Thieme Medical Publishers, Inc., 333 Seventh Avenue, New York, NY 10001, USA.

License terms 
against cerebral palsy (CP) lawsuits, another long-standing birth myth. But the use of a scientifically bankrupt machine solely to benefit physicians when it harms patients is simply an egregious endorsement of obstetric defensive medicinepostmodern ethical relativism solely for the benefit of physicians-and is undeniable proof that bioethical principles are nothing more than empty rhetoric.

\section{A Medical Myth Is Born}

In the 1950s and 1960s, amid the nascent technology revolution, space race, and medicine's conquest of diseases that had tormented the world for generations, several researchers were independently inventing a computer-like fetal heartbeat counter. ${ }^{5,7-9}$ The invention was motivated by the perceived need to replace humans at the heartbeat-counting task of intermittent auscultation during labor. ${ }^{5,7-9}$ Counting fetal heartbeats emanated from an 18th-century unproven theory that asphyxia during labor caused $\mathrm{CP}$ and other neurologic birth maladies. That theory merged into the theory that an abnormal fetal heart rate was a direct, accurate measure of past and present fetal brain damage., ${ }^{5,7}$ The theory soon became dogma. Quick delivery was the cure from the asphyxia causing CP or any other neurologic birth injury. At first, interventions were with forceps and obstetric maneuvers, but that quickly gave way to cesarean sections as surgical techniques and anesthesia improved. ${ }^{5,7,8}$ The EFM inventors, rather than questioning the theories that had been accepted by generations of physicians before them that CP's cause was asphyxia and that abnormal fetal heart rates accurately reflected brain damage, concentrated on counting heartbeats. It is unfortunate that the inventors overlooked proving the dogma, because it is nothing more than myth, fable, and fairy tale. ${ }^{6,8-24}$

\section{Cerebral Palsy's Nemesis}

The EFM inventors did not rely on clinical trials. EFM efficacy was proven by uncontrolled clinical assessments and anecdotes. $5,7,8,16,20,23,24$ Nevertheless, the clinical obstetric community received EFM with enthusiasm, because fetal monitoring did not involve new concepts. EFM merely automated the critical task of heartbeat counting that previously had been done manually. ${ }^{24}$ EFM inventors were even more enthusiastic. They predicted that EFM alone would reduce by half intrapartum deaths, mental retardation, and $\mathrm{CP}^{25}$

\section{A New Medical Phenomenon: Defensive Obstetrics}

In 1970, as EFM began revolutionizing clinical obstetrics, two other seemingly unconnected simultaneous revolutions gained momentum. One was the revolution in legal liability theories and evidence law, which was exponentially expanding medical malpractice lawsuits, causing the first of many malpractice insurance crises. ${ }^{6,9,11,26}$ The second was a slower sea change collapsing the Hippocratic tradition-the physician chooses what is best for the patient-to bioethics, a code based on secular liberal political philosophy-the physician provides the patient with treatment option information, thereby enabling the patient to make medical decisions autonomously. $^{27-29}$ No one knew that these revolutions would merge to create a maelstrom that put trial lawyers, not physicians, in charge of labor room decisions and created a phenomenon previously unknown in medical historydefensive medicine: treatments disguised as medical care that are solely for the physicians' protection from trial lawyers. ${ }^{6,9-11}$

\section{The Perfect Storm}

Before EFM, there was little in the way of obstetric medical malpractice. Intermittent auscultation resulted in recording what the physician heard, and no amount of cross-examination could change a doctor's recollection that the fetal heart tones were normal during labor. EFM changed everything. EFM provided a permanent second-by-second computer-like graph of the entire labor, a graph that years or even decades after birth could be critically analyzed by EFM "experts" who specialized in courtroom obstetrics. These experts could, without fail, deliver neurologically perfect babies every time by performing the just-in-time cesarean section that saved the infant from certain devastation. Defendant physicians, on the other hand, not as capable, well-educated, or attentive as the courtroom experts, sentenced a child to the lifelong neurologic devastation of $\mathrm{CP}$, cognitive diminution, seizures, and other conditions, all because of his or her negligent EFM mismanagement and failure to perform a "simple" cesarean section. Lawsuits multiplied exponentially, as did the amount of the $\mathrm{CP}$ verdicts and settlements, many so enormous they rivaled business litigation lawsuits. ${ }^{6,9-14,19,21}$

Forty years of the EFM-CP punitive litigation cottage industry have enriched trial lawyers and their experts, but rarely the children with $\mathrm{CP}^{10,12,13,15,19,21}$; made physicians and hospitals into a social welfare insurance scheme; driven caregivers away from obstetrics; closed obstetric services to the public; and for more than a generation diverted research away from CP's true causes. ${ }^{6,10-13,15,19,21}$

How? Because physicians, convinced that the birth dogma accepted for multiple generations was the cause of $\mathrm{CP}$, sought to protect themselves by concentrating solely on a system whose inventors promised would defeat $\mathrm{CP}$ and most other birth defects-EFM. Ironically, the choice to make EFM the deus ex machina led inevitably to more and bigger CP verdicts and settlements, multiplying the anxiety level associated with each birth and causing physicians to abandon true patient care in favor of protecting themselves from harm, rather than protecting their patients. ${ }^{20}$

\section{Willful Ignorance}

In 2013, thought leaders in the maternal-fetal medicine community conceded that five decades of EFM research, investigation, and clinical use had failed to reduce the incidence of CP or any other neurologic malady. ${ }^{30}$ EFM had resulted in an exponentially increased cesarean section 
rate, driven primarily by $\mathrm{CP}$-related litigation as well as the realization there was a consistent absence of scientific evidence that interventions in labor based on any single or combination EFM patterns did not prevent $\mathrm{CP}$ or other neurologic impairment. ${ }^{30}$ These scholars conceded that it was time to start over, because, despite a half century of meetings, conferences, and task forces designed to make EFM viable, EFM still lacked common language, standard interpretations, and reasonable management principles and guidelines.

All of the EFM faults outlined by these scholars had been known for decades, but had remained secrets within the medical community, never shared with the millions of mothers undergoing EFM assessments. In fact, the secret EFM faults, flaws, imperfections, and weaknesses were even more sweeping than the maternal-fetal medicine scholars admitted-so sweeping that EFM should have been discarded on the junk science trash heap after the first real clinical trial in 1976 found no EFM benefit but significantly increased cesarean sections. ${ }^{6,9}$ BRPOs' willful blindness and the desire to protect doctors and hospitals from lawsuit are the reason EFM survived. Nevertheless, there was a price to be paid. And it was mothers and babies who paid the price.

\section{Faults, Flaws, and Foibles}

Clinical trials organized years after EFM use had already become popular showed no EFM benefit compared with intermittent auscultation. Between 1976, when the first trial was reported, until 1995, 12 clinical trials found no EFM benefit but a substantially higher cesarean section rate. ${ }^{6,9,11,31}$ Along the way, a few observers plainly told BRPOs and the medical community that $\mathrm{CP}$ was not caused by asphyxia, ${ }^{32}$ that EFM was a failure and a waste of time, $8,17,18,20,21,23$ and that using EFM to deliver babies by cesarean section in response to EFM patterns was causing more harm than good, ${ }^{14,17,19,22}$ and some suggested early in the process that EFM should be abandoned. ${ }^{24}$

But BRPOs and their members ignored that evidence and the evidence that EFM pattern interpretation, even among experts, was contradictory, highly unreliable, and difficult to teach. ${ }^{9,11,31}$ And despite four decades of effort to improve EFM pattern interpretation, it remained subjective, impossible to standardize, poorly reproducible, with inter- and intraobserver contradictions even more problematic today than in the past. $20,33-35$

\section{Protecting Doctors from Lawsuits: The Undisclosed Price}

EFM has consistently produced significantly more cesarean sections than any other method of fetal surveillance. In 1970 , the cesarean section rate was $2 \%^{31}$ In $2013,33 \%{ }^{36}$ Much of that increase was driven by defensive obstetricscesarean sections in any case with a questionable EFM pattern. ${ }^{6,9-14,17,19,21-24}$ Far better to do a cesarean section than be sued for acting slowly. But the plain truth is that $80 \%$ of the EFM patterns are category II, for which BRPOs have no clinical management guidelines or recommendations. ${ }^{30,37-39}$ Clinicians are on their own, with only a good luck wish from their professional societies-the organizations that should be advancing evidence-based medicine and helping their members avoid specious litigation. ${ }^{39}$ But instead BRPOs' 50 years of silence have done everything to assist the plaintiff lawyers waiting on the sidelines for the next physician or nurse perplexed by a machine that confuses everyone in obstetrics, save and except the usual courtroom experts, who never have difficulty interpreting any EFM pattern and know precisely what to do and when to act. ${ }^{19,21,40}$

The act favored by courtroom experts is the cesarean section. Multiple times per year in courtrooms around the world and on thousands of trial lawyer Web sites, courtroom experts save babies from CP with a "simple, quick, safe cesarean section" that never has complications or consequences. The defendant physician, if only he had done the same thing, could have saved the child in the courtroom, wheelchair-bound, blind, deaf, or both, cognitively impaired, and fed through a stomach tube. This testimony appeals to laypeople, jurors, judges, and even many physicians, because they do not perceive the serious risks associated with this major abdominal surgery. ${ }^{41}$ The lay view of cesarean section risks is perhaps best illustrated by the increase of the concierge-like desire for cesarean sections on demand. ${ }^{42}$ And although the attitude that a cesarean section is simple and safe accounts for some of the dramatic cesarean section increase, the primary driver of unnecessary cesarean sections and, therefore, unnecessary risks for mothers and children, is EFM's unbelievable 99\% false-positive rate and physicians' litigation fears. ${ }^{6,9-15,19,21,39,41}$

But for almost half a century practitioners and their BRPOs have ignored EFM's flaws and the fact that nonemergency cesarean sections have double the risk of complications compared with vaginal birth ${ }^{43}$ (bleeding, infection, embolisms, anesthesia reactions, surgical injuries ${ }^{41,44}$ ) and risks in subsequent pregnancies-repeat cesarean sections for life, uterine rupture, operative complications from previous surgery, and placenta previa and accreta. ${ }^{41,44,45}$ Could it be mere coincidence that placenta accrete quadrupled over the past 40 years ( 1 in 2,000 in 1980 to the current 1 in 500 pregnancies, making placenta accreta the most common reason for cesarean hysterectomies in industrialized countries) or is it the cause and effect of mounting lawsuit fears and ethical compromise growing out of unneeded EFM cesarean sections? ${ }^{45}$

But known cesarean section risks may not be all that physicians and hospitals have to fear. A growing body of substantial evidence suggests babies delivered by cesarean section are exposed to risks of future chronic diseases and neuropsychiatric disorders. ${ }^{46-49}$ This risk may be the future price to be paid for willfully ignoring EFM and its contributions to false-positive cesarean sections-an avalanche of suits claiming a child's chronic disease was induced by false EFM signals causing the physician to perform an unnecessary cesarean section.

A half century of research in CP and EFM has exposed the myths, fables, and fairy tales forming the foundation for a 
continuing deceit foist upon mothers and babies by physicians and BRPOs fearful of trial lawyers-so fearful that mothers are given no choice or informed consent about EFM. This medical paternalism supposedly died decades ago, but apparently the reports of its death were greatly exaggerated. As a recent author observed, although EFM is almost certainly fatally flawed, "the overwhelming majority of laboring patients will continue to receive EFM, beneficial or not, in the foreseeable future." ${ }^{50}$

\section{Electronic Fetal Monitor and Medical Ethics: Back to the Future}

EFM was born during a period of perhaps the most rapid advances in medical history, including advances in surgery, medications, organ transplants, genetic engineering, reproductive manipulations, and hundreds of technical advances unimagined even a decade before. At the same time, social and cultural changes stimulated philosophy and theology scholars to join scientists and physicians in questioning the ethical concerns of these rapid medical advances. ${ }^{51}$ During the early part of this period in the late 1960s, the word bioethics was coined as a way of linking scientific advances to human values. ${ }^{51}$ By the end of the 1970 s, bioethics was a new, distinctive discipline with its own literature and its own research centers, with professors of bioethics scattered throughout the world's medical schools. ${ }^{51}$

EFM's birth and insertion into clinical practice occurred before traditional deontology dramatically changed from the revered Hippocratic-based benign paternalism-the physician's duty to determine the best treatment for the patient using only the physician's best judgment-to the new, unfamiliar bioethics of autonomy-the patient's freedom to decide what is in her best interests-and autonomy's partner, informed consent. ${ }^{11,27-29,51}$ Side by side with autonomy emerged two bioethics principles essentially similar to the previous traditional medical ethics-beneficence (acting in the patient's best interest) and nonmaleficence (do no harm). Among the new principles, autonomy and informed consent were the absolute heart of bioethics, replacing the longrevered, ancient Hippocratic instruction to physicians to do what they thought was best for the patient, whether the patient agreed or not. ${ }^{27-29,51}$ In fact, the Hippocratic tradition was solely physician-centered, so much so that even such a luminary as Oliver Wendell Holmes advised his 1871 medical school graduate audience that patients had no right to the medical truth of their condition. ${ }^{27}$ As jarring as that statement may seem today, that was the mind-set of medical ethics as EFM became popular-no need to discuss EFM with mothers, obstetricians know exactly what to do and how to do it. Unfortunately, that attitude has not changed even slightly since the inception of EFM 50 years ago. And this attitudinal truculence is intentional and willful. Through the decades, BRPOs were well aware and were reminded often that EFM was inefficacious, ineffectual, and useless for predicting CP or any other neurologic malady. Moreover, BRPOs were periodically reminded that mothers should be given an informed choice about EFM. BRPOs simply did not respond.
Even today, there remains no BRPO response. Nor has there been any outcry from ethicists.

\section{A Prophet Is Not without Honor}

Only once in EFM's and autonomy's life, 1979, were serious concerns raised in a high-profile National Institute of Child Health (NICH) Task Force formed to investigate antenatal diagnoses, including hereditary disease, congenital defects, and intrapartum fetal distress predictors, one of which was EFM. In its report, the task force emphasized that EFM was unproven and had discernible risks and that data interpretation was problematic at best and likely responsible for the already significant increase in cesarean section. The task force concluded that before EFM use, mothers were entitled to a thorough discussion of benefits, limitations, and risks, and a choice of alternative forms of monitoring. The task force pointedly observed that such discussions should occur during prenatal care and again on admission to the labor suite. ${ }^{52,53}$ Nothing changed.

By 1984, the EFM lack of informed consent controversy was prominent in the legal literature. The medical and legal EFM issues were elegantly elucidated including EFM's futility and medicine's failure to live up to the informed consent autonomy where EFM use was concerned. ${ }^{54}$ Nothing changed.

In 1987, the International Federation of Gynecology and Obstetrics (IFGO), comprised of worldwide obstetrics-gynecologic societies, published its guidelines for the use of fetal monitoring. Echoing the 1979 NICH Task Force, the IFGO also opined that mothers should have informed consent about EFM use, both during antepartum care and again on admission to the labor suite. ${ }^{55}$ Nothing changed.

In 1987, the legal literature again emphasized obstetrics' complete and total failure to include mothers in the EFM discussion matrix, concluding that informed consent in obstetrics was an illusion. ${ }^{56}$ Nothing changed.

Through the ensuing years, the same questions have been raised and discussed and the same conclusions reached. ${ }^{57,58}$ Nothing changed. And because nothing has changed for half a century, the questions continue to be raised even to this day. ${ }^{59}$

\section{Egregious Failure}

This documented EFM ethical failure is egregious. There have been failures of medical ethics in the past-the Tuskegee experiment, plutonium injections, mental health treatments-and all had at least one common theme: the subjects were not told about the experiment. Analogously, mothers are not routinely told about the EFM experiment inflicted in childbirth. And experiment is not too strong a word. What word would accurately describe a medical procedure indicted by its contemporaries for 50 years as being a failure in every decade of its existence? EFM use has done more harm than good and cost more in terms of maternal morbidity and mortality than it has benefited babies $^{14,22}$; EFM interpretation today and in the past, even 
among experts, is subjective, impossible to standardize, poorly reproducible, and contradictory ${ }^{20,33-35,37-39}$; there are no long-term benefits of $\mathrm{EFM}^{1}$; fetal heart rate is a poor measure of past and present fetal brain function and damage $^{10} ; 50$ years of EFM and EFM-induced cesarean sections have not changed the rate of $\mathrm{CP}$ or encephalopathy ${ }^{1,8,10,12-15,17-24}$; as a screening test for absence of injury, EFM is no better than a coin toss ${ }^{14}$; EFM has a huge false-positive rate, a fact known since at least $1979,{ }^{52}$ and quantified at $99 \%$ in 1994 , a percentage never challenged since then ${ }^{6,9,11}$; no data exists in the entire medical literature demonstrating that any intervention based on any single or combination of fetal heart rate patterns reduces the risk of $\mathrm{CP}^{1,22,30}$; a test leading to an unnecessary major abdominal surgery in $99.5 \%$ of cases should be regarded by the medical community as absurd at best ${ }^{22}$; an evolving consensus in the maternal-fetal medicine community concludes it is time to start over with EFM and establish common EFM language, standard EFM interpretations, and EFM management principles and guildelines $^{30}$; EFM does not predict $\mathrm{CP}$, neonatal neurologic injury, stillbirth, or neonatal encephalopathy ${ }^{1,10}$; EFM "harms women," "wastes time and money," and "offers no lasting benefit" to children; and few physicians "would use a pregnancy test (or a home smoke detector) that is wrong almost every time a positive signal appears." 17

\section{Homer Nods; Atlas Shrugs}

The EFM experiment must end. It is past time to recognize that EFM in labor is as much of a medical procedure with potential, real life-and-death choices as any other significant health care treatment. And it is far past time that mothers be told the truth about EFM-it is still experimental. Many may choose EFM. But the choice belongs to mothers, not physicians and hospitals. The few voices from the distant and recent past revealing EFM as an imposter and those calling for informed consent have been intentionally disregarded by BRPOs, physicians, and hospitals because they fear trial lawyers and lawsuits more than they respect their ethical obligations to mothers and babies. And although such fear is neither rational, reasonable, nor ethical, ${ }^{6,9,11}$ at least it is a discernible excuse for 50 years of medical paternalism. Ethicists, on the other hand, have no excuse whatsoever for their silence.

In the half century since bioethics became a concept, then a word, and finally reality, millions of spoken and written words have championed autonomy-the individual's right to self-determination-as the heartbeat of bioethics. But, as so many point out, autonomy cannot possibly exist without timely information. ${ }^{27-29,52-61}$ So the question is, where have the ethicists been for almost a half century as the EFM controversies over efficacy and informed consent played out in the literature and in the real world of childbirth? It is in that real world that physicians and hospitals simply impose their modern-day brand of medical paternalism. Did ethics sleep while the medical world tilted on its axis?

\section{Conclusion}

Myths, fables, and fairy tales aside, medicine has continued its 50-year use of a known scientifically bankrupt machine under the banner that it is a reliable safety device monitoring mothers' and babies' health. But EFM's true purpose is primarily to protect health care providers from trial lawyers; with full knowledge that the machine causes harm to unsuspecting patients, its use is a shocking, flagrant, egregious deception. The fact that only a handful of caregivers who knew about the EFM deception tried over the years to change the paradigm is equally shocking, but not nearly as appalling as the fact that the entire medical ethics field did not listen, much less endeavor to stop the open and obvious EFM patient exploitation and duplicity. EFM's half-century history is simply undeniable proof that defensive medicine-postmodern ethical relativism for physicians' sole benefit-easily trumps the empty rhetoric of bioethics. Today is the day that should end. If not now, when?

\section{Recommendations}

We recommend that an international task force similar to the Neonatal Encephalopathy Task Force ${ }^{1}$ publish a consensus report stating the following: EFM cannot detect the onset of neuropathology, ${ }^{10}$ cannot determine when neuropathology would be reversible or irreversible, ${ }^{10}$ cannot ascertain when earlier delivery by cesarean section would prevent $\mathrm{CP},{ }^{10}$ and that except for obstetric catastrophes (such as maternal cardiac arrest or uterine rupture), EFM pattern interpretation does not reduce the risk of CP in any population. $6,10,11,22$ Such a report would mark the beginning of the end of using EFM pattern interpretation as the standard of care in the world's courtrooms. ${ }^{6,10,11,26}$ More importantly, it would propel EFM clinical pattern interpretation into the medical experimental category where it belongs, thus requiring that mothers give informed consent before EFM use. Physicians would be able to continue using EFM as a labor-saving device over one-on-one auscultation, without the pressure to quickly deliver every baby with a worrisome EFM pattern.

\section{Funding}

The authors received no financial support for the research, authorship, or publication of this article.

\section{References}

1 The American College of Obstetricians and Gynecologists and American Academy of Pediatrics. Neonatal Encephalopathy and Neurologic Outcome. 2nd ed. 2014

2 Ayres-de-Campos D. Introduction: why is intrapartum fetal monitoring necessary-impact on outcomes and interventions. Best Pract Res Clin Obstet Gynaecol 2015; June 23 (Epub ahead of print); doi: 10.1016/j.bpobgyn.2015.05.005

3 Nageotte MP. Fetal heart rate monitoring. Semin Fetal Neonatal Med 2015;20(3):144-148 
4 Berkowitz RL, D'Alton ME, Goldberg JD, et al. The case for an electronic fetal heart rate monitoring credentialing examination. Am J Obstet Gynecol 2014;210(3):204-207

5 Freeman RK, Garite TJ, Nageotte MP, Miller LA. Fetal Heat Rate Monitoring. 4th ed. Philadelphia, PA: Lippincott Williams \& Wilkins; 2012

6 Sartwelle TP, Johnston JC. Neonatal encephalopathy 2015: opportunity lost and words unspoken. J Matern Fetal Neonatal Med 2015; June 22 (Epub ahead of print)

7 Parer JT. Personalities, politics and territorial tiffs: a half century of fetal heart rate monitoring. Am J Obstet Gynecol 2011;204(6): 548-550

8 MacDonald D. Cerebral palsy and intrapartum fetal monitoring. N Engl J Med 1996;334(10):659-660

9 Sartwelle TP. Electronic fetal monitoring: a bridge too far. J Leg Med 2012;33(3):313-379

10 MacLennan AH, Thompson SC, Gecz J. Cerebral palsy: causes, pathways, and the role of genetic variants. Am J Obstet Gynecol 2015; May 21 (Epub ahead of print); doi: 10.1016/j. ajog.2015.05.034

11 Sartwelle TP, Johnston JC. Cerebral palsy litigation: change course or abandon ship. J Child Neurol 2015;30(7):828-841

12 Donn SM, Chiswick ML, Fanaroff JM. Medico-legal implications of hypoxic-ischemic birth injury. Semin Fetal Neonatal Med 2014; 19(5):317-321

13 Badawi N, Keogh JM. Causal pathways in cerebral palsy. J Paediatr Child Health 2013;49(1):5-8

14 Costantine MM, Saade GR. The first cesarean: role of "fetal distress" diagnosis. Semin Perinatol 2012;36(5):379-383

15 MacLennan AHA. A "no-fault" cerebral palsy pension scheme would benefit all Australians. Aust N Z J Obstet Gynaecol 2011; 51(6):479-484

16 Obladen M. Lame from birth: early concepts of cerebral palsy. J Child Neurol 2011;26(2):248-256

17 Grimes DA, Peipert JF. Electronic fetal monitoring as a public health screening program: the arithmetic of failure. Obstet Gynecol 2010;116(6):1397-1400

18 Khalil A, O'Brien P. Fetal heart rate monitoring-is it a waste of time? J Obstet Gynecol India 2006;56(6):481-485

19 MacLennan A, Hankins G, Speer N. Only an expert witness can prevent cerebral palsy. Obstet Gynecol 2006;8(1):28-30

20 Greene MF. Obstetricians still await a deus ex machina. N Engl J Med 2006;355(21):2247-2248

21 MacLennan A, Nelson KB, Hankins G, Speer M. Who will deliver our grandchildren? Implications of cerebral palsy litigation. JAMA 2005;294(13):1688-1690

22 Clark SL, Hankins GD. Temporal and demographic trends in cerebral palsy-fact and fiction. Am J Obstet Gynecol 2003; 188(3):628-633

23 Freeman R. Intrapartum fetal monitoring-a disappointing story. N Engl J Med 1990;322(9):624-626

24 Jenkins HML. Thirty years of electronic intrapartum fetal heart rate monitoring: discussion paper. J R Soc Med 1989;82(4): 210-214

25 Quilligan EJ, Paul RH. Fetal monitoring: is it worth it? Obstet Gynecol 1975;45(1):96-100

26 Johnston JC, Sartwelle TP. The expert witness in medical malpractice litigation: through the looking glass. J Child Neurol 2013; 28(4):484-501

27 Laine C, Davidoff F. Patient-centered medicine. A professional evolution. JAMA 1996;275(2):152-156

28 Veatch RM. The Basics of Bioethics. 3rd ed. Boston, MA: Pearson Education, Inc.; 2012

29 Beauchamp TL, Childress JF. Principles of Biomedical Ethics. 7th ed. New York, NY: Oxford University Press; 2009

30 Clark SL, Nageotte MP, Garite TJ, et al. Intrapartum management of category II fetal heart rate tracings: towards standardization of care. Am J Obstet Gynecol 2013;209(2):89-97
31 Sartwelle TP. Defending a neurologic birth injury. Asphyxia neonatorum redux. J Leg Med 2009;30(2):181-247

32 Illingworth RS. Why blame the obstetrician? A review. BMJ 1979; 1(6166):797-801

33 Sholapurkar SL. Interpretation of British experts' illustrations of fetal heart rate decelerations by Consultant Obstetricians, registrars and midwives: a prospective study-reasons for major disagreements with the experts and implications for clinical practice. Open J Obstet Gynecol 2013;3:454-465

34 Hruban L, Spilka J, Chudacek V, et al. Agreement on intrapartum cardiotocogram recordings between expert obstetricians. J Eval Clin Pract 2015;21(4):694-702

35 Spilka J, Chudáček V, Janků P, et al. Analysis of obstetricians' decision making on CTG recordings. J Biomed Inform 2014;51:72-79

36 Osterman MJK, Kochanek KD, MacDorman MF, Strobino DM, Guyer B. Annual summary of vital statistics: 2012-2013. Pediatrics 2015;135(6):1115-1125

37 Parer JT. Standardization of fetal heart rate pattern management: is international consensus possible? Hypertens Res Pregnancy 2014;2(2):51-58

38 Cahill AG, Roehl KA, Odibo AO, Macones GA. Association and prediction of neonatal acidemia. Am J Obstet Gynecol 2012; 207(3):206.e1-206.e8

39 Maso G, Piccoli M, De Seta F, et al. Intrapartum fetal heart rate monitoring interpretation in labour: a critical appraisal. Minerva Ginecol 2015;67(1):65-79

40 Kesselheim AS, Studdert DM. Characteristics of physicians who frequently act as expert witnesses in neurologic birth injury litigation. Obstet Gynecol 2006;108(2):273-279

41 Spong CY, Berghella V, Wenstrom KD, Mercer BM, Saade GR. Preventing the first cesarean delivery: summary of a joint Eunice Kennedy Shriver National Institute of Child Health and Human Development, Society for Maternal-Fetal Medicine, and American College of Obstetricians and Gynecologists Workshop. Obstet Gynecol 2012;120(5):1181-1193

42 Ecker J. Elective cesarean delivery on maternal request. JAMA 2013;309(18):1930-1936

43 Villar J, Carroli G, Zavaleta N, et al; World Health Organization 2005 Global Survey on Maternal and Perinatal Health Research Group. Maternal and neonatal individual risks and benefits associated with caesarean delivery: multicentre prospective study. BMJ 2007;335(7628):1025-1032

44 American College Obstetricians \& Gynecologists and Society for Maternal Fetal Medicine. Safe prevention of the primary cesarean delivery. Am J Obstet Gynecol 2014;210(3):179-193

45 Silver RM, Fox KA, Barton JR, et al. Center of excellence for placenta accreta. Am J Obstet Gynecol 2015;212(5):561-568

46 Sevelsted A, Stokholm J, Bønnelykke K, Bisgaard H. Cesarean section and chronic immune disorders. Pediatrics 2015;135(1): e92-e98

47 Friedrich MJ. Unraveling the influence of gut microbes on the mind. JAMA 2015;313(17):1699-1701

48 Borre YE, O'Keeffe GW, Clarke G, Stanton C, Dinan TG, Cryan JF. Microbiota and neurodevelopmental windows: implications for brain disorders. Trends Mol Med 2014;20(9):509-518

49 Neu J. The pre- and early postnatal microbiome: relevance to subsequent health and disease. NeoReviews 2013;14(12): e592-e599

50 Devoe LD. Electronic fetal monitoring: does it really lead to better outcomes? Am J Obstet Gynecol 2011;204(6):455-456

51 Jonsen AR. A Short History of Medical Ethics. New York, NY: Oxford University Press; 2000

52 Zuspan FP, Quilligan EJ, Iams JD, van Geijn HP. NICHD Consensus Development Task Force report: predictors of intrapartum fetal distress-the role of electronic fetal monitoring. J Pediatr 1979; 95(6):1026-1030

53 Zuspan FP, Quilligan EJ, Iams JD, van Geijn HP; Report of the National Institute of Child Health and Human Development 
e34 Perpetuating Myths, Fables, and Fairy Tales Sartwelle et al.

Consensus Development Task Force. Predictors of intrapartum fetal distress: the role of electronic fetal monitoring. Am J Obstet Gynecol 1979;135(3):287-291

54 Gilfix MG. Electronic fetal monitoring: physician liability and informed consent. Am J Law Med 1984;10(1):31-90

55 International Federation of Gynaecology and Obstetrics and Family Health International. Guidelines for the use of fetal monitoring. Int J Gynaecol Obstet 1987;25:159-167. Available at: http://www. geburtshilfe.usz.ch/Documents/HealthProfessionals/Guidelines/ fetal_monitoring.pdf. Accessed July 11, 2015

56 Rhoden NK. Informed consent in obstetrics: some special problems. West New Engl Law Rev 1987;9(1):67-88
57 Wood SH. Should women be given a choice about fetal assessment in labor? MCN Am J Matern Child Nurs 2003;28(5):292-298, quiz 299-300

58 Heelan L. Fetal monitoring: creating a culture of safety with informed choice. J Perinat Educ 2013;22(3):156-165

59 Abrams JR. The illusion of autonomy in women's medical decisionmaking. Fla State Univ Law Rev 2015;42:17-60

60 Grady C. Enduring and emerging challenges of informed consent. N Engl J Med 2015;372(9):855-862

61 Schenker Y, Meisel A. Informed consent in clinical care: practical considerations in the effort to achieve ethical goals. JAMA 2011; 305(11):1130-1131 